\title{
Relationship between Self-Esteem and Indulgence in Behavior Problems among Secondary School Students in Kenya
}

\author{
Dr John Agwaya Aomo \\ Kitutu Central Sub-County Education Office, \\ Kisii, Kenya \\ Dr Peter J.O. Aloka \\ Psychology \& Educational Foundations, \\ Jaramogi Oginga Odinga University of Science \& Technology \\ Dr Pamela A. Raburu \\ Psychology \& Educational Foundations, \\ Jaramogi Oginga Odinga University of Science \& Technology \\ Dr Peter O. Ogolla \\ HomaBay County Director, ECDE, \\ Homabay, Kenya
}

Doi: $10.2478 / \mathrm{mjss}-2018-0055$

\begin{abstract}
The study investigated the relationship between students' self-esteem and indulgence in behavior problems in Kenya. The Theory of Planned Behaviour by Ajzen, and Person Centered Theory by Carl Rogers were employed to guide the study. A concurrent triangulation design was adopted. The SelfEsteem Scale and indulgence in behavioral problems questionnaire were used to collect data for the study. Interview schedule were used to collect data from the students. A sample size of 378 was students drawn from girls, mixed and boys' schools where boys to be used in the study will be $60 \%$ which is (270), and girls $40 \%$ (155). Quantitative data was analyzed by using inferential statistics such as Pearson product moment correlation coefficient while qualitative data was analyzed by using the thematic framework. The findings indicated a plausible negative $(r=-.564)$ correlation between students' self-esteem and his/her indulgence in behaviour problems. Thus students with high level of self-esteem were associated with low level of indulgence in behaviour problems. The study recommended that, the parents also should identify the best parenting practices that promote students' self-esteem so that at school level they will be fully adjusted to following learning instructions other than involving in behaviour problems.
\end{abstract}

Keywords: relationship; students; self-esteem; indulgence; behavior problems; Kenya

\section{Introduction}

Generally, many students operate their homes irrespective of their cultures or countries of origin; for instance, a 1994 national survey in Suburban; Urban and rural Schools in the United States of America found that the major factors were held responsible for school violence disintegration of 
family and increased depiction of violence in the media and popular music. In Kisii County, students behavioral problems leading to destruction of property, interference of learning programs, psychological and academic achievement have been reported from several schools since 2011 (CDE's Office Kisii County, 2014). Educational programs requires that students live in an environment where they are peaceful and are instructed with the right knowledge, skills values and attitudes (Abiero, 2009). However, in the past student behavior problems have been seen to increase and have become a challenges to almost all stakeholders in education(Kangare, 2008), the student behavior problems have resulted into death, destruction of property, deformities, truancy among students, and interference with the learning and teaching in schools (Ruto,2009). A lot of studies have been done on students' behavioral problems touching bullying, aggressiveness and delinquency, strikes, anti-social behavioral (Elliot and Cornell, 2009, Ruto, 2009, Kangare, 2008) all these are extrinsic variables of student behavioral problems. Studies done in Western Kenya by Wasangulu, Agak, Kabuka, 2011, Chemeli, 2014,) all focused on extrinsic management and causes of students behavior problems. However, few studies have focused on the students' self-esteem leading to indulgence into behavior problems.

Ajzen (1988) in his Theory of Planned Behavior (IPB) proposes a model which can measure how human actions are guided. It also predicts the occurrence of behavior as intentional (Ajzen, 1991). This theory came about when it was realized that there was a discrepancy between attitude and behavior, therefore, this theory of planned behavior was introduced to predict behavior because behavior can be deliberative and planned (Ajzen 1988). Carl Rogers (1951) stated that all individuals exist in a continually changing world of experience (phenomenal field) of which they are the Centre. The organism reacts to the field as it is experienced and perceived. This perceptual field is "reality" for the individual and that the organism reacts as an organized whole to the phenomenal field. A portion of the total phenomenal field gradually becomes differentiated a the self. The theory posited by Rogers (1951) informs the study that individual's behavior (students) is patterned by the kind of perceptual experiences they hold towards the environment to which they interact with. The quality of interaction with others (fellow students, teachers and parents) will depend on their internal state (intrinsic variables) and how they are perceived in the phenomenal world. The theory also maintains that students will struggle to achieve their basic needs accompanied by emotions which consequently facilitates goal-directed behavior.

Duo (2007) study in Norway showed that there was a significant correlation between student self-esteem and behavior problem. Witt (2012) in their study showed that women in effort condition actually believed they were hungrier than the comparison group; they had two ways to justify their higher consumption. The study revealed that self-licensing effect seems to be one that can lead to troubles without knowing. Coskun (2009) indicated there was significant negative relationship among anger expression and social support and trait anger perceived from family and teachers and between self-esteem and trait anger.

Sara, (2005) revealed a significant positive relationship between self-esteem and control, that students with high self-esteem were able to control their anger. Sava Koppejan (2011) revealed that victimization by cyber bullying and colonization with the mother are associated with self-esteem and perceived stress and that good communication with the mother does not have protective effect on the associations. Rapelang, Kagiso, Cedric, Mpho, Nonofo, Sathunya, Kolentino and Balagun (2013) study in Botswana High self-esteem exhibited low correlations with the afore-mentioned sexual behaviors. Rawson (2014) reiterated that, indicated that, within this sample, measures of children's depression, external locus of control and anxiety all were inter correlated positively to a moderately high level. Measures of self-esteem were correlated significantly and negatively with depression and anxiety, but had little correlation with external locus of control. Aneela (2013) also argued that, low self-esteem would be associated with high substance use and high self-esteem would be associated with lower substance use. Castillo, vazsonyi and Jenkins (2008) showed that self-esteem, risks- proneness and educational commitment were highly associated with measures of violent and criminal behaviours in both samples. Ozdemir (2012) reiterated that behavioral control positively predicted, self-esteem. 


\section{Research Methodology}

A Concurrent Triangulation design was used to collect data, this design allowed the collection of quantitative and qualitative data at the same time (Terrel, 2012). Target population consisted of 11479 form three students drawn from three sub counties: Sameta, Kisii Central and Gucha South in the following proportion; (20\%) 2295.8, (50\%) 5739.5 and (30\%) 3443.7 respectively. Using solving formula, a total of 95 secondary schools are targeted to participate in the study.40 teachers and 20 principals will be included in the study to respond to interview schedule and questionnaires. Therefore, student sample size was 378 students drawn from girls, mixed and boys' schools where boys to be used in the study was $60 \%$ which is (270), and girls $40 \%(155)$. The study used simple random sampling procedures to select students and teachers to participate in the research study.

The questionnaires adopted for data collection included: Sorensen Self-Esteem Questionnaire and Indulgence in Behavior Problem Questionnaire. The study used Sorensen self-esteem questionnaire where the respondents were required to click place a check next to the number of each statement he/she find to be true, the questionnaire helped to find out the students' self-esteem and indulgence in behavior problems, questionnaire consisted of 25 items in Likert scale to which students will be expected to check as Strongly Agree, Agree, Neutral, Strongly Disagree, and Disagree (Kasomo, 2007). The study also used interview schedule to collect qualitative data to twenty (20) students and guidance and counseling heads of departments in the selected schools. This process was facilitated by open ended questionnaires to allow the respondents give the thoughts and feelings about students' behavior problems. The trustworthiness of qualitative data was ensured through Triangulation and divergent constructions of reality that exist within the context of the study as information is collected about different events and relationship from different point of view.

Before commencing the study the researcher sought a written permission from School of Post Graduate Studies, Jaramogi Oginga Odinga University of Science and Technology and then proceed to National Council of Science, Technology and Innovation to request for authority to carry out research as required by the law. After obtaining authority, the researcher visited County Director of Education (CDE) Kisii to obtain a letter of introduction and permission to conduct a study within the county. Then, after the permission granted, the researcher visited the sub-counties and schools to inform them of the intended research, and also to create rapport and solicit their co-operation. On the date of questionnaire administration, the researcher, personally and with other two assistants distribute the instruments to the students, teachers, and principals of the selected schools. Quantitative data was analyzed by using inferential statistics such as Pearson product moment correlation coefficient while qualitative data was analyzed by using the thematic framework.

\section{Findings \& Discussions}

The second objective of the study was to establish the relationship between students' self- esteem and student indulgence in behavior problems. To explore the students' self-esteem an instrument used was a twenty eight-itemed Likert-scaled questionnaire of five options. The options of the selfesteem scale (Strongly Agree, Agree, Neutral, Disagree and Strongly Disagree) were used to assess the respondents' views on various indicators of aspects of indulgence in behaviour problem. Frequency percentages of the responses on the measuring scale was computed. Table 1 shows the summary of percentages of students' responses on self-esteem.

Table 1: Percentage Frequency of Responses On Self-Esteem

\begin{tabular}{|c|c|c|c|c|c|}
\hline Questions/items & $\begin{array}{l}\text { Strongly } \\
\text { agree }\end{array}$ & Agree & Jeutra & isagree & $\begin{array}{l}\text { Strongly } \\
\text { disagree }\end{array}$ \\
\hline $\begin{array}{l}\text { generally feel anxious in new social situations where I may not know what } \\
\text { is expected of me. }\end{array}$ & 37.1 & 30.0 & 32.9 & 0.0 & 0.0 \\
\hline I find it difficult to hear criticism about myself. & 47.1 & 20.0 & 12.2 & 20.7 & 0.0 \\
\hline I fear being made to look like a fool & 51.1 & 48.9 & 0.0 & 0.0 & 0.0 \\
\hline I tend to magnify mistakes and minimize my successes. & 34.3 & 32.9 & 0.0 & 0.0 & 32.9 \\
\hline
\end{tabular}




\begin{tabular}{|c|c|c|c|c|c|}
\hline Questions/items & $\begin{array}{l}\text { Strongly } \\
\text { agree }\end{array}$ & Agree & Veutral & isagree & $\begin{array}{l}\text { Strongly } \\
\text { disagree }\end{array}$ \\
\hline I am very critical of myself and others. & 0.0 & 34.3 & 32.9 & 0.0 & 32.9 \\
\hline I have periods in which I feel devastated and/or depressed. & 0.0 & 32.9 & 0.0 & 34.3 & 32.9 \\
\hline I am anxious and fearful much of the time. & 10.0 & 39.5 & 0.0 & 46.3 & 4.2 \\
\hline $\begin{array}{l}\text { When someone mistreats me I think that I must have done something to } \\
\text { deserve it. }\end{array}$ & 0.0 & 10.5 & 0.0 & 41.1 & 48.4 \\
\hline I have difficulty knowing who to trust and when to trust. & 26.5 & 0.0 & 20.0 & 14.3 & 39.2 \\
\hline I often feel like I don't know the right thing to do or say. & 20.4 & 20.0 & 0.0 & 34.3 & 25.3 \\
\hline I am very concerned about my appearance. & 34.3 & 0.0 & 32.9 & 0.0 & 32.9 \\
\hline I am easily embarrassed. & 32.9 & 34.3 & 0.0 & 0.0 & 32.9 \\
\hline I think others are very focused on- and critical of-what I say and do. & 51.1 & 0.0 & 0.0 & 0.0 & 48.9 \\
\hline I fear making a mistake which others might see. & 34.3 & 20.0 & 0.0 & 10.0 & 35.7 \\
\hline $\begin{array}{l}\text { I often feel depressed about things l've said and done, or things I failed to } \\
\text { say or do. }\end{array}$ & 30.8 & 20.2 & 20.0 & 15.5 & 13.5 \\
\hline $\begin{array}{l}\text { I have avoided making changes in my life because I was fearful of making } \\
\text { a mistake or failing. }\end{array}$ & 17.2 & 9.8 & 0.0 & 20.0 & 53.0 \\
\hline I often get defensive and strike back when perceives I am being critical. & 29.0 & 0.0 & 10.0 & 20.4 & 40.6 \\
\hline I have not accomplished what I am capable of due to fear and avoidance. & 0.0 & 0.0 & 32.9 & 34.3 & 32.9 \\
\hline I tend to let fear and anxiety controls many of my decisions. & 51.1 & 0.0 & 0.0 & 0.0 & 48.9 \\
\hline I tend to think negatively much of the time. & 0.0 & 0.0 & 0.0 & 34.3 & 65.7 \\
\hline $\begin{array}{l}\text { I have found it difficult to perform adequately or without embarrassment } \\
\text { when involved in sex. }\end{array}$ & 0.0 & 0.0 & 65.7 & 0.0 & 34.3 \\
\hline $\begin{array}{l}\text { I am one of the following: the person who reveals too much personal } \\
\text { information about myself of the person who seldom reveals personal } \\
\text { information. }\end{array}$ & 0.0 & 32.9 & 0.0 & 34.3 & 32.9 \\
\hline I often get so anxious that I don't know what to say. & 32.9 & 0.0 & 34.3 & 32.9 & 0.0 \\
\hline I often procrastinate. & 32.9 & 34.3 & 0.0 & 32.9 & 0.0 \\
\hline I try to avoid conflict and confrontation. & 0.0 & 0.0 & 32.9 & 0.0 & 67.1 \\
\hline I've been told I am too sensitive. & 34.3 & 0.0 & 32.9 & 32.9 & 0.0 \\
\hline I felt inferior or inadequate as a child. & 0.0 & 32.9 & 32.9 & 0.0 & 34.3 \\
\hline I tend to think that I have higher standards than others. & 27.3 & 0.0 & 21.0 & 22.6 & 31.1 \\
\hline
\end{tabular}

The findings of the study show that many students generally feel anxious in new social situations where they may not know what is expected of them. This was reflected by the majority (strongly agree: $37.1 \%$; agree: $30.0 \%$ ) of the students respondents who supported the researchers' assertion that people are generally apprehensive in new situations. This echoes Rwanson (2014) who measured the manifest of anxiety, self-esteem locus of control depression among children with behavioral and emotional problems, the result showed that children's depression, external locus of control, and anxiety all were inter correlated hence many students could anxiety in this case. However, nearly a third $(32.9 \%)$ of the respondents remained neutral on whether or not they feel nervous in new social situations. It emerged from the study findings that generally they are as many people being nervous as are those who are not nervous. While about half $(49.5 \%)$ of the respondents agreed that they are generally anxious and fearful much of the time, about another half $(50.5 \%)$ of respondents said they were neither anxious nor fearful in most of situations.

On the same note, more than a half $(51.1 \%)$ of the students respondents strongly agreed that they tend to let fear and anxiety control many of their decisions, but nearly another half $(48.9 \%)$ of the respondents strongly refuted that claim. The group who accepted that fear and anxiety control their decisions, agreed that they often get so anxious that they don't know what to say. This was reflected by $32.9 \%$ of the respondents who said anxiety and fear are real. Although about a third $(32.9 \%)$ of the respondents indicated that they were not critical of themselves and others, a significant proportion (34.3\%) of the students who participated in the study agreed that they were quite critical of themselves and others, but $32.9 \%$ of the respondents remained undecided on the matter. However, on the contrary, majority $(47.1 \%)$ of the respondents strongly agreed and a fifth $(20 \%)$ of them just agreed that they find it difficult to hear criticism about them. Only about a fifth $(20.7 \%)$ of them said they did not mind hearing people criticizing them and $12.2 \%$ of them were not sure how they would feel when they hear people criticize them. What came out clearly from all the students respondents was fear of being fooled; all the respondents (strongly agree: $51.1 \%$; agree: $48.9 \%$ ) accepted that they fear being made to look like a fool.

The results of study indicate that majority of the respondents fear making a mistake which 
others might see, as reflected by more than a third $(54.3 \%)$ of the respondents who supported the statement, but $45.7 \%$ of them negated the statement. $51 \%$ of the respondents alluded that they often feel depressed about things they have said and done, or things they failed to say or do, a fifth $(20 \%)$ of them remained undecided but only $29 \%$ denied they often feel depressed as a result of things they said/did or failed to say/do. A significant majority $(67.2 \%)$ of the respondents generally agreed that they often procrastinate, but $32.9 \%$ of them alluded that they rarely procrastinate on things they meant to do. On the flip flop, it was revealed from the findings of the study that people limit their abilities due to fear of failure. More than two thirds $(67.2 \%)$ of the respondents agreed that they tend to magnify mistakes and minimize they successes. However, on the same note but a different point of view, nearly a third $(32.9 \%)$ of the respondents strongly disagreed that they have had not accomplished what they were capable of achieving due to fear and avoidance. About a fifth $(20.4 \%)$ of respondents strongly agreed that they often feel like they don't know the right thing to do or say most of the times, however about a quarter $(25.3 \%)$ of the respondents strongly refuted the claim. It also emerged from the findings of the study that although majority $(53 \%)$ of the respondents strongly refuted the claim that they avoided making changes in their life because they were fearful of making a mistake or failing, a significant proportion $(27 \%)$ of the respondents accepted that they avoided making changes in their life for fear of failing.

The findings of the study show that many people have low self-esteem. For example, nearly two thirds $(65.8 \%)$ of the respondents agree that they felt inferior or inadequate as a child, only $34.3 \%$ of them felt otherwise. Mahyuddin (2006) argued that both self-esteem and self-efficacy and future time perspective were related to students' risky sexual behavior problems. About a third $(32.9 \%)$ of the respondents agree that they seldom reveal personal information about them, however another $(32.9 \%)$ of the respondents said they reveal too much personal information about themselves. Majority (51.1\%) of the respondents think others are very focused on- and critical ofwhat they say and do, but the other $48.9 \%$ did not care what other people think about them. In fact, while $34.3 \%$ of the students who participated in the study were very concerned about their appearance, $32.9 \%$ of them were less concerned on their appearance. On the same note, whereas $32.9 \%$ of the respondents disagreed that they were easily embarrassed, $67.1 \%$ of them agreed that they were easily embarrassed.

It was also established that a significant population of students often get defensive and strike back when they perceive that they are being criticized. This was noted by $29 \%$ of the students who participated in the study. However, the majority $(40.6 \%)$ of the students who took part in the study alluded that they accept criticism. In addition, $34.3 \%$ of the respondents accept that people perceive them as being too sensitive, but $32.9 \%$ of them remained undecided on this matter, as another $32.9 \%$ of them saying they were not too sensitive, as perceived by other people. More than half $(53.7 \%)$ of the respondents think that they were of low standard than others, however, $27.3 \%$ of them tend to think that they have higher standards than others and $21 \%$ of them remained noncommittal on their thought. Marilyn et al (2011) examined relationship between dispositional traits and attitudes towards cheating among university students in USA, the result indicated that gender, degree of idealism, relativism and machiavellian traits were found to influence students attitudes towards cheating. This an implication that student's indulgence in behavior problems is related to their intrinsic capacity emanating from their attitudes.

On the issue of sex, the study findings show that most of the respondents, being students, did not have the experience. This was reflected by the majority $(65.7 \%)$ of respondents who remained neutral on the matter. However, for those who could have been involved in sex, they disagreed that they have found it difficult to perform adequately or without embarrassment when involved in sex. Pertaining to the aspect mistreatment, majority (disagree: $41.1 \%$; strongly disagree: $48.4 \%$ ) of the respondents denied that when someone mistreats them they think that they must have done something to deserve it. Slightly more than a quarter $(26.5 \%)$ of the respondents insisted that they had difficulty in knowing who to trust and when to trust, however $39.2 \%$ of respondents said it was not a problem in recognizing who and when to trust. However, a fifth of the respondents remained undecided on the matter.

To test the hypothesis that, "there is no statistically significant relationship between students' self-esteem and indulgence in behavior problems", a bivariate correlation (zero-order correlation) 
was used to explore the relationship between the two variables. This was done by computing a Pearson Product-Moment Correlation Coefficient. It was used to establish whether there was any significant relationship between the scores of self-esteem, as measured by soreness self-esteem test questionnaire, and students' indulgence to behavior problems. Table 2 shows SSPS out of the Pearson product moment correlation.

Table 2: Correlations between self-esteem and indulgence to behaviour

\begin{tabular}{|l|l|c|c|}
\hline \multicolumn{2}{|c|}{} & Self-esteem & Indulgence to behaviour \\
\hline \multirow{3}{*}{ Self-esteem } & Pearson Correlation & 1 & $-.564 "$ \\
\cline { 2 - 4 } & Sig. (2-tailed) & & .000 \\
\cline { 2 - 4 } & $\mathrm{N}$ & 347 & 347 \\
\hline \multirow{3}{*}{ Indulgence to behaviour } & Pearson Correlation & $-.564 "$ & 1 \\
\cline { 2 - 4 } & Sig. (2-tailed) & .000 & 347 \\
\cline { 2 - 4 } & $\mathrm{N}$ & 347 & \multicolumn{2}{|l}{} \\
\hline \multirow{2}{*}{$*$. Correlation is significant at the 0.01 level (2-tailed). }
\end{tabular}

The study established a plausible negative $(r=-.564)$ correlation between students' self-esteem and his/her indulgence in behavior problems. As indicated in Table 4.8, the analysis revealed a highly significant $(p<0.05)$ negative relationship between the two variables, with high level of selfesteem associated with low level of indulgence in behavior problem. This finding is similar to Coskun (2009) who contends that there was a significant negative relationship among anger expression and social support and trait anger perceived from the family and teachers and between self- esteem and trait anger. Sava KOppejan (2011) also showed that cyber bullying had a negative effect on adolescents who reported communication problems with their mothers. On the same note Beatrice (2013) similarly reported that emotional intelligence did not significantly predict victimization behavior by controlling for age, gender, and parental attachment and self-esteem. Rapelang e $t$ a I (2013) agrees that high self-esteem exhibited low correlation with a fore mention sexual behaviors, and the multiple regression analysis also showed that self - efficacy had stronger predictive power on the on the safe sex behaviors under study in comparison to high self-esteem. However, Duo (2007) indicated in his report that there was a significant correlation between student self- esteem and behavior problems which was supported by Coskun (2009) who showed that there was appositive relationship between self-esteem and control, and that students with high selfesteem were able to control their anger than students with low self-esteem, this echoed Afobi e $t$ al (2014) who also found that there was moderate positive relationship between parenting styles, self-esteem and adolescent tendency to bullying behavior.

To get an idea of how much variance the two variables share, a coefficient of determination was computed. It was established that the two variables share $(-.564 \times-.564=.3180)$, which implied $R^{2}=31.8$ per cent of their variance. This showed that there was a reasonable overlap between the two variables; implying that students' self-esteem alone help to explain nearly 32 per cent of the variance in respondents' scores on the indulgence to behaviour problems. This was quite a significant amount of variance explained by only one independent variable (self-esteem).

The qualitative data was obtained from ten principals, ten deputies' principals and ten heads of guidance and counseling teachers. Most participants reported that self-esteem of the student influences their behavior, that students who have high self-esteem are well behaved in most cases. The participants felt that students with high self- esteem set for themselves higher goals and they concentrate in academic work, therefore, not indulgence in behavior problems. For example, two respondents' reported that; "Students with high self-esteem are always well behaved (Principal, 3). "Students of high self-esteem do great things away from behavioral deviance (HOD/GC, 2)". In behavior problem in school, on the other participants also reported that, students with low selfesteem are always found in behavior problems. For example, four of the respondents reported that, "Students with low self-esteem always do poorly in class activities and sometimes become lonely and may not want to associate with others" (HOD/GC, 3). "Students with low self-esteem do indulge 
and engage in activities against school regulations" (Principal, 4) "Students with low-self-esteem are easily carried off by those with high-self-esteem" (Principal, 5) "Students with low self-esteem are more likely to indulge in behavior problems as away of getting along with other peer (HOD/GC, 4). "A student with low self-esteem may end up becoming a truant because they don't have selfdriven principles" (Principal, 6).

From the participant's responses, it is coming out that students with low self-esteem are always carried away by others, do poorly in class, and therefore, they are found to easily indulge in activities that expose them to behavior problems. This finding agrees with Rapelang e $t$ al (2013) who reported that students with high self-esteem exhibited low correlation with fore mention sexual behaviors as opposed tom students with low self-esteem who easily found themselves in behavior problems. This was further supported by Duo (2009) who reported that there was significant correlation between students' self-esteem and behavior problems. Similarly Coskun (2009) showed that there was a significant positive relationship between self-esteem and control, and that students with high self-esteem were able to control their anger as opposed to students with low self-esteem. Wandal (2010) in USA investigated relationship between family transition, conduct problems, selfesteem and academic competence elementary age African American boys, the result showed that there was no significant relationship between transition and students misconducts/ self-esteem or academic performance.

\section{Conclusion \& Recommendation}

The study established a plausible negative correlation between students' self-esteem and his/her indulgence in behavior problems. The analysis revealed a highly significant $(p<0.05)$ negative relationship between the two variables, with high level of self-esteem associated with low level of indulgence in behavior problems. The qualitative interviews showed that students with low selfesteem were always carried away by their peers, perform poorly in class and therefore, were found to indulgence in activities that expose them to behavior problems. The result also showed that students with high level of self-esteem were associated with low level of indulgence in behavior problems. The study recommended that, the parents also should identify the best parenting practices that promote students' self-esteem so that at school level they will be fully adjusted to following learning instructions other than involving in behaviour problems.

\section{References}

Kangare, W. (2008). Sexual Violence in Kenya. Nairobi, Kenya: Nairobi Publishers.

Ruto, B.M. (2009) Relationship Between Management and Strikes In Secondary Schools of Uganda; A case study of Ntungamo District. Unpublished Masters Degree, Kampala, Makerere University.

Wasangulu, M.P. Agak J.O. \& Kabuka E.K. (2011) Perceived Home Factors Contributing Behaviour among Public Secondary Students In Western Province, Kenya, Maseno University.

Elliot and Cornell (2009). Bullying in Middle Schools as A Function of Insecure Attachment and Aggressive Attitudes. USA, School of Psychology International, 30,201-214.

Chemeli P. (2013). An Assessment of the relationship Between Students Personality Types And Career Aspirations in Eldoret most District, Kenya, Eldoret, Eldoret Polytechnic.

Coskun, A. (2009). Anger-self-esteem and perceived social support in adolescence, Selenk University, Konya, Turkey; Social behavior and personality 2009, 37(4) 555-564.

Sara, D. (2007). Relationship between Self- Esteem and Indirect Aggression In The Work Place, Gordon Hart, Temple. University: Journal of Psychiatry and Psychology; vol. 1, issue 1, 256-266.

Sava, K. (2011). Bullying effects on self-esteem, perceived stress and role of Communication with the mother. Utrecht University - Master Kinder- en Jeugdpsychologie.

Rapelang C., Tihabano, K, vista, C. Pheko, M. Losoke, N. Sethunya, M. Mpeta, K \&

Balagun, K. (2013). Self-efficacy, self-esteem and intention to practice safe sex among Botswana Adolescents: 10SR. Journal of Humanities and social science (10SR-JHSS)Vol.9, Issue 2 (Mar- april.2013), PP.87-95.

Rawson, E.H (2014). The Interrelationship of Measures of Manifest Anxiety, Self-Esteem, Locus of Control, And Depression In Children With Behavior Problems. Behaviour Journal, Vol, 23, pages, 25-36.

Ozdemir, (2012). Parental behavioural and psychological control relationships to self-Esteem life satisfaction, depression, and antisocial behaviours, rent home > volume 9, No. 2 (2012) > Ozdemiv 
Castillo, E.T, Vazsconyi \& Jenkins (2008). Violent and criminal behaviours in Rural and non-rural African American Youth: A risk -Protective factor approach. Journal of Southern Rural Sociology 23(2) 2008, pp $108-130$.

Aneela, A. (2013). Relationship between substance use and self -esteem; International Journal of scientific and engineering Research Vol. 4, Issue2, ISSN 229-5518.

Kasomo, D. (2007). Research Methods in Humanities and Education. Kenya Kijape Printers.

Terrel, S (2012). Mixed methods: Research methodologies. Nova South Eastern, Ft Lauderdale, Florida, U.S.A. 